\title{
On European electricity market liberalization: A game-theoretic approach*
}

\author{
K. Staňková, G.J. Olsder, and B. De Schutter
}

If you want to cite this report, please use the following reference instead: K. Staňková, G.J. Olsder, and B. De Schutter, "On European electricity market liberalization: A game-theoretic approach," INFOR: Information Systems and Operational Research, vol. 48, no. 4, pp. 267-280, Nov. 2010.

Delft Center for Systems and Control Delft University of Technology

Mekelweg 2, 2628 CD Delft

The Netherlands

phone: +31-15-278.24.73 (secretary)

URL: https://www.dcsc.tudelft.nl

*This report can also be downloaded via https://pub. deschutter.info/abs/11_003.html 


\title{
On European Electricity Market Liberalization:
}

\section{A Game-Theoretic Approach}

\author{
Kateřina Staňková \\ Delft Center for Systems \& Control \\ Delft University of Technology \\ Mekelweg 2, 2628 CD Delft \\ The Netherlands \\ k.stankova@tudelft.nl \\ Geert Jan Olsder \\ Delft Institute of Applied Mathematics \\ Delft University of Technology \\ Mekelweg 4, 2628 CD Delft \\ The Netherlands \\ g.j.olsder@tudelft.nl \\ Bart De Schutter \\ Delft Center for Systems \& Control \\ Delft University of Technology \\ Mekelweg 2, 2628 CD Delft \\ The Netherlands \\ b.deschutter@tudelft.nl
}

\begin{abstract}
In this paper we deal with the European electricity market liberalization problem, formulated as a game with electricity producers as players, while the consumers' electricity demand is exogenous. The producers maximize their profit by choosing how much electricity they will produce individually by means of electricity production available to them. The aim of the research presented in this paper is to investigate the differences between the resulting electricity prices with different scenarios: a market with one Stackelberg leading producer, a market with two Stackelberg leading producers being noncooperative among themselves, and a perfectly competitive market. In the case studies the games involving one, two, and eight European countries are played. In the scenarios dealt with in this paper the perfectly competitive market yields the lowest electricity prices for the consumers. However, we also discuss possible drawbacks of liberalization. Our research aims to help understanding the complex process of electricity market liberalization.
\end{abstract}

Keywords: electricity market liberalization, perfect competition, Nash equilibrium, Stackelberg equilibrium 


\section{Introduction}

Since the early 1990s, the electricity market in the European Union Member States has been undergoing a process of liberalization, largely spurred by the European Commission with the aim of ensuring greater competitiveness and pushing prices downwards. Consequently, European countries have gone through reasonably comprehensive privatization, restructuring and deregulation programs in sectors that were previously regulated monopolies and/or state-owned: e.g., airlines (Dodgson, 1994), telecommunications (Eliassen and Sjovaag, 1999), postal services (Beschorner and Ernst, 2008), or railroads (Szekely, 2009). In this paper we will focus on electricity sector liberalization. In many European countries the electricity sector reforms are incomplete, either moving forward slowly with considerable resistance or moving backward, despite the success of these reforms in the United Kingdom and the Nordic countries (Van Eck, 2007; Joskow, 2008). Currently, the speed and the current state of liberalization vary among different European countries, from a near monopoly in some countries in central, east, and south eastern Europe (Koroneos and Nanaki, 2007; Ganev, 2009; Pollitt, 2009) to highly competitive markets in England and Wales (Green, 2005; Newbery, 2006) or Norway and Sweden (Bye and Hope, 2005; Amundsen and Bergman, 1998; Leveque, 2007).

The original goals of liberalization were to bring benefits to consumers by lowering electricity prices and to cause more cost-efficient electricity production (Van Eck, 2007). When electricity restructuring and competition programs are designed and implemented well, electricity sector performance, in terms of operating costs, physical network losses, generator availability, availability of service, investment, price levels and structures, service quality, and other performance variables, can be expected to improve significantly compared to either the typical state-owned or private regulated monopoly (Van Damme, 2005; Joskow, 2008). However, the experience in many countries makes it clear that successful implementation of liberalization reforms is not easy and that there is a risk that costly performance problems may emerge when the transformation is implemented incompletely or incorrectly (Koroneos and Nanaki, 2007; Joskow, 2008). Additionally, little is known about the environmental consequences of liberalization. On the one hand, more cost-efficient production may be beneficial for the environment, while on the other hand, lower market prices may result in higher electricity demand, which increases the burden on the environment. Moreover, in a highly competitive market an incentive to produce electricity with cheap, but often environment-unfriendly means, is increased.

Extensive studies of electricity market models have been carried out by other researchers. In (Neuhoff et al., 2005) the Belgian, Dutch, French, and German electricity market are considered and the effects of market power among three different models are compared. One of these models, the nodal pricing static equilibrium model COMPETES, is additionally studied in (Hobbs et al., 2004a,b, 2005; Ekeberg et al., 2003) and in (Kromann, 2001) the consequences of market power in the Nordic electricity market are considered. In (Boots et al., 2004) and (Egging and Gabriel, 2006) a gametheoretic model of the European gas market is presented. In (Chen and Hobbs, 2005) a nodal pricing model with emission permit trading is developed to study strategic effects of holding $\mathrm{NO}_{\mathrm{x}}$ permits. In (Lise et al., 2006) the electricity market with 8 European countries is considered. The decision variables of the individual electricity producers are the so-called market power mark-ups, which determine the "strength" of individual producers.

This paper is based on the electricity market game presented in (Staňková, 2009) 
and introduces a noncooperative game between electricity producers, while the electricity price for a given electricity load is uniform within each country. The electricity producers choose electricity amounts to be produced in different load periods by different means of production in order to maximize their profit. The consumers' electricity demand is assumed to be exogenous. Such assumption is reasonable in the situation in which the selling price of electricity is uniform per country and per peak load, i.e., the consumers within the same country cannot choose "cheaper" electricity from different producers. Because the electricity trade between neighboring countries is allowed, the producers may interact not only with other producers belonging to the same country, but also with producers located in neighboring countries. Three different game-theoretic scenarios of the behavior of the electricity producers will be formulated, namely a perfect competition (with symmetric players), a Stackelberg game, in which in each country one electricity producer acts as a first-moving Stackelberg market leader, and a Stackelberg game with two leading producers per country, being noncooperative among themselves.

The number of producers per country is given, as well as parameters such as electricity production costs and electricity production capacities, and the emission factors per country and per technology. These initial data are derived from real data that were taken from existing literature and electronic sources (Lise et al., 2006; European Transmission System Operators, 2007). Additionally, shadow prices on emissions per energy producer can be set.

While the game is formulated for a general set of countries, in the case studies we consider situations in which producers of only one country (The Netherlands), of two countries (Belgium, The Netherlands), and of eight countries (Belgium, Denmark, Finland, France, Germany, The Netherlands, Norway, and Sweden) are involved. These eight countries were chosen because real data about electricity prices, emission factors, and electricity producers for these countries are available (European Transmission System Operators, 2007). Moreover, there already exist case studies involving these countries in an alternative approach introduced in (Lise et al., 2006). Therefore, we can compare our results with already existing results presented in (Lise et al., 2006). The main difference between the Lise's model and our model is that while in the former model the producers' decisions are the so-called market power mark-ups and both technologies and production levels for the producers are fixed, in our case the producers' decision variables are amounts of electricity to be produced by alternative technologies and therefore the producer can also decide not to produce the electricity by some of the means available to him, if such means do not bring him profit. Moreover, the different behavioral patterns than those considered in (Lise et al., 2006) are dealt with.

The contributions of the research presented in this paper can be listed as follows:

- A new game-theoretic model of the electricity market is developed. Our approach differs from those presented in the existing literature, in which other types of markets, electricity markets with fewer countries included in the model, or different decision variables for the electricity producers are considered.

- Various game types, like a perfect competition case or a Stackelberg game with one leading producer and the rest of the producers being perfectly competitive, are dealt with.

- Most of the input data for our model come from real measurements presented in existing literature. Therefore, the improved version of the model can help to explain some recent changes in the real European electricity market. 
This paper is organized as follows. In Section 2 a model of European electricity market in 8 European countries is formulated. In Section 3 various case studies are performed. The relation of the outcomes to the situation in the current European electricity market, and possible future research directions are discussed in Section 4.

\section{Games of the European electricity market}

\subsection{Basics}

Let us consider a one-shot game with electricity producers (also referred to as firms or companies) in different countries (also referred to as regions) as players. The electricity producers sell electricity to their customers. The electricity price for a specific time does not vary within the country, while the electricity price within a country may vary with respect to the customers' electricity demand, which is assumed to be exogenous. Depending on the electricity demand we talk about the specific electricity load mode (e.g., the so-called peak load when the electricity demand is high and the so-called base load when the electricity demand is low).

The number of producers for each country is given. To each producer a set of available electricity production technologies and maximum amount of electricity that the producer can produce is assigned a priori. A producer maximizes its payoffs by choosing the amount of electricity to produce by each available technology for each possible load. Producer's payoff is the difference between the revenues from selling electricity and the costs of production. The amount of electricity, which a producer can produce, is constrained. In particular, producers distinguish between two separate markets based on the electricity demand, namely peak hours and base hours. The prices of electricity differ across countries and load periods and in addition these prices might depend on the level of the total electricity demand in a country during a particular load period. This dependency reflects particular strategic behavior of the electricity producers. The firms base their decision on the amount of electricity produced given the load period, technology and market.

International electricity trade is only feasible with neighboring countries and includes netting, which means that bi-directional electricity flows between two countries are permitted, as long as trade (transmission) constraints, defined a priori, are not violated. Certain electricity production technologies create emissions. The producers have to pay a fee if their emission production is above the emission limit known a priori.

Let $F$ and $R$ be a set of firms and a set of regions included in the model, respectively. Let $F_{r} \in F$ be a set of firms located in region $r$. Let $I$ be a set of possible technologies for electricity generation. Let $I_{r} \subset I$ be a set of technologies that are available in region $r \in R$, and let $I_{f} \in I_{r}$ be a set of technologies available to firm $f$ located in region $r$. Let $L$ be a set of possible load modes and let $U_{r}$ denote a set containing region $r$ and its neighboring countries. Let $K$ be a set of possible emissions produced by all the electricity production technologies considered.

Producer $f \in F_{r}$ maximizes its profit $\mathscr{J}_{f}[€]$ defined as (Staňková, 2009)

$$
\mathscr{J}_{f} \stackrel{\text { def }}{=} \sum_{l \in L} h_{l} \sum_{r^{\prime} \in R} p_{r^{\prime}, l} s_{f, r^{\prime}, l}-\sum_{l \in L} h_{l} \sum_{r^{\prime} \in R} \sum_{i \in I_{f}} c_{i, r} q_{i, f, r^{\prime}, l}
$$

where $s_{f, r, l}[\mathrm{GW}]$ denotes the supply of electricity of load mode $l$ from producer $f$ into country $r$ and $p_{r, l}[€ / \mathrm{GWh}]$ denotes the unit electricity market price for country $r$ and load mode $l$. Moreover, $h_{l}[\mathrm{~h}]$ denotes the number of hours belonging to load $l$ per 
year, $c_{i, r}[€ / \mathrm{GWh}]$ represents the variable production costs with technology $i$ in region $r$, in which producer $f$ is located, while $q_{i, f, r^{\prime}, l}[\mathrm{GW}]$ is the production of producer $f$ with technology $i$ for region $r^{\prime}$ for load mode $l$. The supply of electricity of load mode $l$ per producer $f$ to region $r^{\prime}$ denoted by $s_{f, r^{\prime}, l}$ is defined as

$$
s_{f, r^{\prime}, l} \stackrel{\text { def }}{=}\left(1-\lambda_{r^{\prime}}\right) \sum_{i \in I} q_{i, f, r^{\prime}, l},
$$

where $\lambda_{r^{\prime}} \in[0,1]$ is the loss of electricity due to its transport to region $r^{\prime}$, known in advance. Moreover, the electricity supply is additive, i.e., the total electricity supply $S_{r^{\prime}, l}[\mathrm{GW}]$ for load mode $l$ per region $r^{\prime}$ can be computed as

$$
S_{r^{\prime}, l}=\sum_{f \in F_{r^{\prime}}} s_{f, r^{\prime}, l} .
$$

The production of electricity is limited to the maximum operational electricity capacity owned by the producer. The consumers are assumed to be price-sensitive, i.e., the electricity demand in each country is dependent on the current price of electricity. Therefore, we define the demand function as a constant elasticity of substitution (CES) function (Arrow et al., 1961; Armington, 1969; Lise and Linderhof, 2004), which depends on the price elasticity of demand $\varepsilon_{r, l}>0$, the reference demand for electricity $d_{r, l}^{0}[\mathrm{GWh}]$, and the reference price of electricity $p_{r, l}^{0}[€ / \mathrm{GWh}]$ :

$$
S_{r, l}=d_{r, l}^{0}\left(\frac{p_{r, l}}{p_{r, l}^{0}}\right)^{-\varepsilon_{r, l}} .
$$

The price elasticity of demand determines the slope of the consumers' demand curve and therefore it indicates the change in quantity of electricity demanded by customers in response to change in its price.

Note that we can distinguish different demand functions per country and per load period.

\subsection{Constraints on electricity production and trade}

The electricity producers in our model are assigned to a specific country. Hence, no crossborder ownership is permitted. There is an opportunity to trade electricity among countries, with the following restrictions:

- Trade via imports and exports to countries outside the considered countries is ignored.

- A producer can only trade with neighboring countries.

The amount of electricity traded $x_{r, r^{\prime}, l}[\mathrm{GW}]$ is defined as the difference between the exported amount of electricity from region $r$ to region $r^{\prime}$ and the imported amount of electricity entering region $r$ from region $r^{\prime}$, i.e.,

$$
x_{r, r^{\prime}, l}=\sum_{f \in F_{r}} \sum_{i \in I} q_{i, f, r^{\prime}, l}-\sum_{f^{\prime} \in F_{r^{\prime}}} \sum_{i \in I} q_{i, f^{\prime}, r, l} .
$$

The amount of electricity traded is complementary to the shadow price $\tau_{r, r^{\prime}, l}$. This shadow price obtains a nonnegative value, when the trade restriction reaches the trade capacity:

$$
\tau_{r, r^{\prime}, l}\left(x_{r, r^{\prime}, l}-x_{r, r^{\prime}}^{\max }\right)=0, \quad \tau_{r, r^{\prime}, l} \geq 0, \quad x^{\max } \geq x_{r, r^{\prime}, l}
$$


with the maximum amount of electricity traded between regions $r$ and $r^{\prime}$ denoted by $x_{r, r^{\prime}}^{\max }[\mathrm{GW}]$.

We assume that the maximum production capacity is complementary to the shadow price $\mu_{i, f, l}[€ / \mathrm{GWh}]$, which has a nonnegative value if the production with technology $i$, by company $f$ during load mode $l$ reaches the production capacity:

$$
\mu_{i, f, l}\left(\sum_{r^{\prime} \in R} q_{i, f, r^{\prime}, l}-q_{i, f}^{\max }\right)=0, \quad \mu_{i, f, l} \geq 0, \quad q_{i, f}^{\max } \geq \sum_{r^{\prime} \in R} q_{i, f, r^{\prime}, l} .
$$

Emissions are also limited. Due to the Kyoto protocol and agreements following it, firms have to reduce the amount of emissions, where the shadow price of emission constraint $\kappa^{k}[€ / \mathrm{GWh}]$ is nonzero as soon as the current amount of emissions is equal to a permissible emission ceiling $E^{k}[\mathrm{~g}]$,

$$
\begin{array}{r}
\kappa^{k}\left(\sum_{l \in L} h_{l} \sum_{r^{\prime} \in R} \sum_{i \in I} \sum_{f \in F} \sigma_{i, r}^{k} q_{i, f, r^{\prime}, l}-E^{k}\right)=0, \quad \kappa^{k} \geq 0, \\
E^{k} \geq \sum_{l \in L} h_{l} \sum_{r^{\prime} \in R} \sum_{i \in I} \sum_{f \in F} \sigma_{i, r}^{k} q_{i, f, r^{\prime}, l} .
\end{array}
$$

Emission factors $\sigma_{i, r}^{k}[\mathrm{~g} / \mathrm{GWh}]$ are associated with the region, in which firm $f$ produces electricity and are given.

The transmission capacity within a country is unrestricted.

\subsection{Maximization problem}

If we include constraints (4), (5), and (6) into the problem of maximizing (1), producer $f$ maximizes profit $L_{f}$ defined as

$$
\begin{aligned}
L_{f} \stackrel{\text { def }}{=} \sum_{l \in L} h_{l} \sum_{r^{\prime} \in R} \sum_{i \in I}\left(p_{r^{\prime}, l}\left(1-\lambda_{r^{\prime}}\right) q_{i, f, r^{\prime}, l}-c_{i, r} q_{i, f, r^{\prime}, l}\right) & \\
& -\sum_{l \in L} h_{l} \sum_{i \in I_{f}} \mu_{i, f, l}\left(\sum_{r^{\prime} \in R} q_{i, f, r^{\prime}, l}-q_{i, f}^{\max }\right) \\
& -\sum_{l \in L} h_{l} \sum_{\substack{r^{\prime} \in R \\
r^{\prime} \neq r}} \tau_{r, r^{\prime}, l}\left(\sum_{f^{\prime} \in F_{r}} \sum_{i \in I_{f}} q_{i, f^{\prime}, r^{\prime}, l}-\sum_{f^{\prime} \in F_{r^{\prime}}} \sum_{i \in I_{f^{\prime}}} q_{i, f^{\prime}, r, l}-x_{r, r^{\prime}}^{\max }\right) \\
& -\sum_{k \in K} \kappa^{k}\left(\sum_{l \in L} h_{l} \sum_{r^{\prime} \in R} \sum_{i \in I} \sum_{f^{\prime \prime} \in F} \sigma_{i, r}^{k} q_{i, f^{\prime \prime}, r^{\prime}, l}-E^{k}\right) .
\end{aligned}
$$

\subsection{Necessary condition to produce electricity}

By taking the derivative of (7) with respect to $q_{i, f, r^{\prime}, l}$ we obtain the Karush-KuhnTucker conditions for maximizing the objective function:

$$
\begin{aligned}
& 0=q_{i, f, r^{\prime}, l}\left(c_{i, r}+\mu_{i, f, l}+\tau_{r, r^{\prime}, l}+\sum_{k \in K} \kappa_{k} \sigma_{i, r}^{k}-\left(1-\lambda_{r^{\prime}}\right) p_{r^{\prime}, l}\left[1-\frac{\pi_{f, r^{\prime}, l}}{\varepsilon_{r^{\prime}, l}}\right]\right), \\
& 0 \leq q_{i, f, r^{\prime}, l}, \quad c_{i, r}+\mu_{i, f, l}+\tau_{r, r^{\prime}, l}+\sum_{k \in K} \kappa_{k} \sigma_{i, r}^{k} \leq\left(1-\lambda_{r^{\prime}}\right) p_{r^{\prime}, l}\left[1-\frac{\pi_{f, r^{\prime}, l}}{\varepsilon_{r^{\prime}, l}}\right]
\end{aligned}
$$


where the market share $\pi_{f, r, l}$ is defined as

$$
\pi_{f, r, l}=\frac{s_{f, r, l}}{\sum_{f^{\prime} \in F_{r}} s_{f^{\prime}, r, l}} .
$$

The inequalities (8) can be interpreted as follows: As long as the marginal revenues from electricity sales are not lower than the marginal costs of production, a power company is willing to produce electricity. The marginal costs for the firm $f$ are

$$
c_{i, f, r^{\prime}, l}^{m}=c_{i, r}+\mu_{i, f, l}+\tau_{r, r^{\prime}, l}+\sum_{k \in K} \kappa^{k} \sigma_{i, r}^{k} .
$$

The four components of the marginal costs can be interpreted as follows. The first term are the costs of the producing electricity. The second and third term are the scarcity price of maximum production capacity per technology and the transmission price related to trade, respectively. The fourth term represents the emission penalty.

We substitute the marginal costs (9) into equation (8) to obtain the following necessary condition for firm $f$ to produce electricity:

$$
\begin{aligned}
& q_{i, f, r^{\prime}, l}\left(c_{i, f, r^{\prime}, l}^{m}-\left(1-\lambda_{r^{\prime}}\right) p_{r^{\prime}, l}\left[1-\frac{\pi_{f, r^{\prime}, l}}{\varepsilon_{r^{\prime}, l}}\right]\right)=0, \\
& q_{i, f, r^{\prime}, l} \geq 0, \quad c_{i, f, r^{\prime}, l}^{m} \leq\left(1-\lambda_{r^{\prime}}\right) p_{r^{\prime}, l}\left[1-\frac{\pi_{f, r^{\prime}, l}}{\varepsilon_{r^{\prime}, l}}\right] .
\end{aligned}
$$

Therefore, as long as the marginal revenues from electricity sales are higher than the marginal costs of production, a producer is willing to produce electricity.

\subsection{Game scenarios}

We will consider three possible games among the electricity producers: a perfect competition $(\mathrm{P})$, a Stackelberg game with one leader per country (S), in which the rest of the producers is perfectly competitive, and a Stackelberg game with two leaders per country (competitive among themselves), where the rest of the producers are also perfectly competitive (NS). The amount of electricity produced by firm $f \in F_{r}$ for region $r^{\prime}$, load mode $l$, and technology $i \in I$ will be denoted as follows:

- $q_{i, f, r^{\prime}, l}^{\mathrm{P}}$ for perfect competition (P);

- $q_{i, f, r^{\prime}, l}^{\mathrm{S}}$ for Stackelberg game with one leader per region (S);

- $q_{i, f, r^{\prime}, l}^{\mathrm{NS}}$ for Stackelberg game with two noncooperative leaders playing per region (NS).

\subsubsection{Perfect competition}

In a perfectly competitive market the electricity producers act as players on the same level. They enter the game if their utility from the game is nonnegative. The problem 
(P) of any electricity producer $f \in F_{r}(r \in R)$ is:

$$
\begin{aligned}
\min _{i, f, r^{\prime}, l} & p_{r^{\prime}, l}(\cdot), \\
\text { s.t. } & q_{i, f, r^{\prime}, l} \geq 0, \\
& q_{i, f, r^{\prime}, l} \leq q_{i, f, r^{\prime}, l}^{\max }, \\
& q_{i, f, r^{\prime}, l}\left(c_{i, f, r^{\prime}, l}^{m}-\left(1-\lambda_{r^{\prime}}\right) p_{r^{\prime}, l}\left[1-\frac{\pi_{f, r^{\prime}, l}}{\varepsilon_{r^{\prime}, l}}\right]\right) \geq 0,
\end{aligned}
$$

for each $f \in F_{r}, i \in I_{r}, l \in L, r^{\prime} \in U_{r}$. The solution of the problem (P) then satisfies

$$
\left(q_{i, f, r^{\prime}, l}^{\mathrm{P}}\right)^{*}=\underset{q_{i, f, r^{\prime}, l} \in \mathscr{S}^{(\mathrm{P})}}{\arg \min } p_{r^{\prime}, l}(\cdot)
$$

where $\mathscr{S}^{(\mathrm{P})}$ is the set given by (11)-(13).

Trivially it follows that at least one $q_{i, f, r^{\prime}, l}$ will be equal to zero.

\subsubsection{Stackelberg game with one leader per region}

We assume that there is one leading firm $f_{\mathrm{S}}$ in each region $r \in R$ acting as the first player, choosing $\left(q_{i, f_{\mathrm{S}}, r^{\prime}, l}^{\mathrm{S}}\right)_{i \in I_{r}, r^{\prime} \in U_{r}, l \in L}$ so as to maximize $L_{f}$ defined in (7), whereas other producers, which are the followers, are perfectly competitive. The leader can determine in advance how the other producers will react to its decision and with this information the leader can choose its optimal $\left(q_{i, f_{\mathrm{S}}, r^{\prime}, l}^{\mathrm{S}}\right)_{i \in I_{r}, r^{\prime} \in U_{r}, l \in L}$.

The problem of the leading electricity producer $f_{\mathrm{S}} \in F_{r}$ is:

$$
\begin{aligned}
\max _{q_{i, f_{\mathrm{S}}, r^{\prime}, l}} & L_{f_{\mathrm{S}}}(\cdot) \\
\text { s.t. } & q_{i, f, r^{\prime}, l} \geq 0 \\
& q_{i, f, r^{\prime}, l} \leq q_{i, f, r^{\prime}, l}^{\max } \\
& q_{i, f, r^{\prime}, l}\left(c_{i, f, r^{\prime}, l}^{m}-\left(1-\lambda_{r^{\prime}}\right) p_{r^{\prime}, l}\left[1-\frac{\pi_{f, r^{\prime}, l}}{\varepsilon_{r^{\prime}, l}}\right]\right) \geq 0
\end{aligned}
$$

for each $i \in I_{r}, l \in L, r^{\prime} \in U_{r}$. The solution of the problem (S) then satisfies

$$
\left(q_{i, f_{\mathrm{S}}, r^{\prime}, l}^{\mathrm{S}}\right)^{*}=\underset{q_{i, f_{\mathrm{S}}, r^{\prime}, l} \in \mathscr{S}(\mathrm{S})}{\arg \min } L_{f_{\mathrm{S}}}(\cdot)
$$

where $\mathscr{S}^{(\mathrm{S})}$ is the set given by (14)-(16).

\subsubsection{Stackelberg game with two leaders per region}

We assume that there are two leading firms $f_{\mathrm{S}}^{(1)}, f_{\mathrm{S}}^{(2)} \in F_{r}$ acting first, being noncooperative among each other and choosing $\left(q_{i, f_{\mathrm{S}}^{(1)}, r^{\prime}, l}^{\mathrm{NS}}\right)_{i \in I_{r}, r^{\prime} \in U_{r}, l \in L},\left(q_{i, f_{\mathrm{S}}^{(2)}, r^{\prime \prime}, l}^{\mathrm{NS}}\right)_{i \in I_{r}, r^{\prime \prime} \in U_{r}, l \in L}$ so as to maximize their profits $L_{f_{\mathrm{S}}^{(1)}}$ and $L_{f_{\mathrm{S}}^{(2)}}$. Other producers, which are perfectly competitive, choose their production amounts per load and technology after the leaders have made their choice. 
The problem of a leading electricity producer $f_{\mathrm{NS}}^{(j)} \in F_{r}, j \in\{1,2\}$, is:

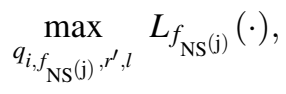

$$
\begin{aligned}
& \text { s.t. } q_{i, f, r^{\prime}, l} \geq 0 \text {, } \\
& q_{i, f, r^{\prime}, l} \leq q_{i, f, r^{\prime}, l}^{\max }, \\
& q_{i, f, r^{\prime}, l}\left(c_{i, f, r^{\prime}, l}^{m}-\left(1-\lambda_{r^{\prime}}\right) p_{r^{\prime}, l}\left[1-\frac{\pi_{f, r^{\prime}, l}}{\varepsilon_{r^{\prime}, l}}\right]\right) \geq 0,
\end{aligned}
$$

for each $i \in I_{r}, l \in L, r^{\prime} \in U_{r}$. The solution of the problem (NS) then satisfies

$$
\left(q_{\left.i, f_{\mathrm{NS}} \mathrm{S}\right)}^{\mathrm{S}}, r^{\prime}, l\right)^{*}=\underset{q_{i, f} \mathrm{NS}_{(\mathrm{j})}, r^{\prime}, l \in \mathscr{S}^{(\mathrm{NS})}}{\arg \min } L_{\mathrm{S}_{\mathrm{S}}(\mathrm{j})}(\cdot),
$$

where $\mathscr{S}^{(\mathrm{NS})}$ is the set given by (17)-(19).

For the sake of simplicity we will assume that the perfectly competitive players have the same production technologies available as well as the same capacities of their productions, which makes them identical players in the considered perfect competition.

In each of the three games we are interested not only in the payoffs for individual players, but also in how their behavior influences emission levels, what technologies to produce electricity would be preferred, and what amounts of electricity will be traded among neighboring countries.

Data known in advance are reference consumers' demand of electricity per region, supply data (generation capacity per firm and per region, cost, technologies available for each firm), trade data (interconnection capacity), distribution losses data, and emission factors. These data are taken from (Staňková, 2009; Van Eck, 2007; Lise et al., 2006; European Transmission System Operators, 2007), and will be introduced in Section 3.1 .

\subsection{Discussion about the model}

In our model electricity demand is represented by a CES demand function, which depends on three parameters: reference demand, reference price, and price elasticity of demand. We distinguish different demand functions per country and per peak load.

The most sensitive parameter in the demand function is the elasticity, because it defines responsiveness of consumers to changes in electricity price and because it has to be established a priori.

In the case studies of this paper, the price elasticity of demand is assumed to have a constant value $\varepsilon_{r, l}=0.4$, which is the same for base and peak load. This value is based on average values found in the literature (Andersson, 1997; Pineau and Murto, 2003) and is often assumed in other studies (Hobbs et al., 2004a,b; Lise et al., 2006). One might argue that this value of price elasticity is rather high, but as explained in (Pineau and Murto, 2003), a price elasticity of 0.4 reflects well the alternatives for consumers to choose their electricity supplier.

It may be reasonable to consider elasticities for peak load demand much higher than those for base load demand. Calibration of price elasticities of demands for different countries and load modes is out of the scope of this paper but is an interesting direction for future research. 
We remark that less elastic demands open opportunities for electricity producers to act strategically as the consumers do not react very fast to price changes. Consequently, the producers are expected to realize much higher payoffs whenever the demands for electricity are rather price inelastic.

\section{Case studies}

\subsection{Input data}

The following countries are considered in the case studies: Belgium (BEL), Denmark (DEN), Finland (FIN), France (FRA), Germany (GER), The Netherlands (NLD), Norway (NOR), and Sweden (SWE). The additional data concerning individual producers, e.g., electricity means available for individual producers, are taken from (Lise and Linderhof, 2004). Within the electricity markets of the considered countries we distinguish 34 different electricity producers, as presented, together with net losses $\lambda_{r}$ values for reference demands $d_{r}^{0}$, and values for reference prices $p_{r}^{0}$, in Table 1.

We assume that there are two possible loads: base load and peak load and consequently we consider different demand functions for both load periods. The demand side of the model consists of one sector per national market. However, there are different markets for peak load (high demand) and base load (moderate demand). Per year there are $h=365 \cdot 24=8760$ load hours to be served. We assume that $20 \%$ of the year concerns peak load, i.e., $h_{\text {peak }}=1752$ hours and the remaining $80 \%$ of the year concerns base load, i.e., $h_{\text {base }}=7008$ hours. In addition, we assume that demand at peak hours in region $r$ requires $90 \%$ of total available capacity: $d_{r \text {,peak }}^{0}=0.9 \sum_{f} \sum_{i} q_{i, f}^{\max }$. Also, we assume that the price of electricity under base load is $90 \%$ of the average price: $p_{r \text {,base }}^{0}=0.9 p_{r}^{0}$. Then, the reference demand at base hours, $d_{r, \text { base }}^{0}$ and the reference price of electricity at peak hours, $p_{r \text {,peak }}^{0}$, are given by the following two equations:

$$
\begin{gathered}
d_{r, \text { base }}^{0}=\frac{d_{r}^{0} h-d_{r, \text { peak }}^{0} h_{\text {peak }}}{h_{\text {base }}}, \\
p_{r, \text { peak }}^{0}=\frac{p_{r}^{0} d_{r}^{0} h-p_{r, \text { base }}^{0} d_{r, \text { base }}^{0} h_{\text {base }}}{d_{r, \text { peak }}^{0} h_{\text {peak }}} .
\end{gathered}
$$

The values of peak and base prices and loads are also presented in Table 1.

The interconnection capacity among countries of the electricity network (Table 2) is restricted and the data is derived from (Lise et al., 2006). The price elasticity of the demand is assumed to be set to -0.4 , which should reflects the alternatives for consumers to choose their electricity supplier (Van Eck, 2007).

We will consider 12 different production technologies, which can be divided into the following groups:

- conventional thermal power technologies: nuclear $(N)$, coal $(C)$, gas $(G)$, lignite (L), oil (O).

- combined heat and power production (CHP) technologies: gas (CHP-G), coal (CHP-C), oil (CHP-O), biomass (CHP-B), and other fuels (CHP-X).

- renewable technologies: hydro $(\mathrm{H})$ and wind power $(\mathrm{W})$. 
Due to varying fuel and production taxes across countries the variable production costs differ across regions and technologies, but not across producers within each country. A summary of the total production capacities in the countries included in the model is given in Table 3. The variable production costs per technology are listed in Table 4. Here empty cells reflect the absence of particular technologies in a country, while values " 0.00 " indicate that the technology in the considered country is cheaper than 0.01 $€ / \mathrm{MWh}$.

\begin{tabular}{lllllllll}
\hline & BEL & DEN & FIN & FRA & GER & NLD & NOR & SWE \\
\hline number of firms & 2 & 3 & 3 & 2 & 5 & 5 & 7 & 7 \\
\hline net losses & $4.5 \%$ & $6.5 \%$ & $3.5 \%$ & $6.8 \%$ & $4.7 \%$ & $3.9 \%$ & $8.9 \%$ & $8.2 \%$ \\
\hline demand (GW) & & & & & & & & \\
average & 9.04 & 3.75 & 8.72 & 46.88 & 54.45 & 11.48 & 12.66 & 15.46 \\
peak load & 8.49 & 2.66 & 8.03 & 38.14 & 50.17 & 10.87 & 12.28 & 14.06 \\
base load & 11.21 & 8.11 & 11.49 & 81.83 & 71.56 & 13.94 & 14.20 & 21.07 \\
\hline price (€/ MWh) & & & & & & & & \\
average & 39.65 & 17.41 & 14.88 & 20.81 & 18.19 & 39.65 & 12.25 & 14.26 \\
peak load & 35.69 & 15.67 & 13.39 & 18.72 & 16.37 & 35.69 & 11.03 & 12.83 \\
base load & 51.67 & 19.69 & 19.04 & 24.68 & 23.29 & 52.01 & 16.49 & 18.06 \\
\hline
\end{tabular}

Table 1: Characteristics of 8 European electricity markets (from the year 2000).

Three environmental effects are taken into account in the game: greenhouse gas emissions, acidification, and smog formation due to emissions of fine particles.

Information about emission factors for all technologies per country is listed in Tables 5, 6, and 7. For all technologies, the specific emissions of the 8 considered countries due to the electricity generation were determined. Emissions due to construction and deconstruction of power plants, mining, extraction, and transportation have been disregarded, as these emissions, including emissions of extraction and transportation, are rather small, and in the same range of those for wind or hydroelectric power. Consequently emissions of hydroelectric, nuclear, and wind power are set to zero, $\mathrm{CO}_{2}$ emissions of biomass power are also set to zero.

\subsection{Considered scenarios and their solutions}

For each problem (P), (S), (NS) the following three scenarios will be considered.

- There is only one country in the model (The Netherlands), i.e., the players are

\begin{tabular}{ccccccccc}
\hline & BEL & DEN & FIN & FRA & GER & NLD & NOR & SWE \\
\hline BEL & & & & 2.50 & & 1.40 & & \\
DEN & & & & & 1.75 & & 0.95 & 1.90 \\
FIN & & & & & & & 0.07 & 1.45 \\
FRA & 2.85 & & & & 1.15 & & & \\
GER & & 1.35 & & 1.75 & & 3.30 & & \\
NLD & 1.40 & & & & 3.30 & & & \\
NOR & & 0.95 & 0.07 & & & & & 3.035 \\
SWE & & 1.84 & 2.05 & & 0.55 & & 3.035 & \\
\hline
\end{tabular}

Table 2: Transmission capacities between the countries in the year $2000(\mathrm{GW})$. 


\begin{tabular}{lllllllll}
\hline & BEL & DEN & FIN & FRA & GER & NLD & NOR & SWE \\
\hline nuclear & 5.71 & & 2.64 & 63.18 & 21.37 & 0.45 & & 9.46 \\
coal & 2.95 & 5.10 & 2.29 & 12.69 & 17.86 & 4.05 & & \\
lignite & & & & & 18.97 & & & \\
gas & 3.50 & 0.04 & 0.90 & 1.89 & 13.82 & 7.17 & & \\
oil & 1.20 & 0.79 & 1.24 & 12.23 & 8.11 & 0.99 & & 4.64 \\
CHP-gas & 0.58 & 2.58 & 1.80 & & 0.99 & 4.66 & & 0.13 \\
CHP-coal & & 1.13 & 1.47 & & 6.96 & & & 0.56 \\
CHP-oil & 0.10 & & 0.16 & & 0.30 & & & 0.65 \\
CHP-bio & 0.29 & 0.23 & 1.04 & & & 0.64 & & 0.46 \\
CHP-other & & & 1.44 & 6.64 & & & 0.20 & 1.00 \\
hydro & 1.40 & 0.01 & 2.88 & 25.60 & 11.61 & 0.04 & 27.46 & 16.33 \\
wind & 0.01 & 2.42 & 0.04 & 0.08 & 0.36 & 0.44 & 0.01 & 0.25 \\
\hline total & 15.74 & 12.30 & 15.89 & 122.31 & 100.33 & 18.44 & 27.67 & 33.48 \\
\hline
\end{tabular}

Table 3: Electricity production capacities in the year 2000 (GW).

\begin{tabular}{lllllllll}
\hline & BEL & DEN & FIN & FRA & GER & NLD & NOR & SWE \\
\hline nuclear & 6.14 & & 6.14 & 6.14 & 6.14 & 6.14 & & 7.50 \\
coal & 16.94 & 13.83 & 13.97 & 15.19 & 14.42 & 16.83 & & \\
lignite & & & & & 15.50 & & & \\
gas & 24.22 & 23.81 & 20.28 & 23.83 & 29.04 & 23.25 & & \\
oil & 36.42 & 35.21 & 35.21 & 38.84 & 38.70 & 41.21 & & 39.83 \\
CHP-gas & 13.29 & 13.08 & 11.21 & & 15.85 & 12.78 & & 13.52 \\
CHP-coal & & 7.57 & 7.63 & & 7.84 & & & 11.73 \\
CHP-oil & 19.58 & 19.58 & 19.58 & & 21.43 & & & 21.58 \\
CHP-bio & 19.94 & 19.94 & 19.94 & & & 19.94 & & 19.94 \\
CHP-other & & & 14.59 & 16.69 & & & 16.69 & 16.69 \\
hydro & 0.00 & 0.00 & 0.00 & 5.84 & 0.00 & 0.00 & 0.00 & 1.18 \\
wind & 0.00 & 0.00 & 0.00 & 0.00 & 0.00 & 0.00 & 0.00 & 0.00 \\
\hline
\end{tabular}

Table 4: Variable production cost (€/MWh) per technology in the year 2000.

\begin{tabular}{lllllllll}
\hline & BEL & DEN & FIN & FRA & GER & NLD & NOR & SWE \\
\hline coal & 920.0 & 972.2 & 915.9 & 915.9 & 970.0 & 915.9 & & \\
lignite & & & & & 1219.7 & & & \\
gas & 388.0 & 327.2 & 348.9 & 401.9 & 348.9 & 411.0 & & \\
oil & 877.3 & 692.6 & 877.3 & 756.8 & 877.3 & 877.3 & & 877.3 \\
CHP-gas & 330.6 & 673.9 & 528.3 & & 327.1 & 327.1 & & 327.1 \\
CHP-coal & & 948.9 & 776.1 & & 33.1 & & & 733.1 \\
CHP-oil & 503.4 & & 503.4 & & 503.4 & & & 503.4 \\
CHP-bio & 0.0 & 81.9 & 2.1 & & & 0.0 & & 0.0 \\
CHP-other & & & 1296.1 & 401.6 & & & 403.4 & 403.4 \\
\hline
\end{tabular}

Table 5: Greenhouse gas emission factors $\left(\mathrm{kg} \mathrm{CO}_{2}\right.$ equivalents/MWh) per technology. 


\begin{tabular}{lllllllll}
\hline & BEL & DEN & FIN & FRA & GER & NLD & NOR & SWE \\
\hline coal & 31.594 & 20.699 & 23.310 & 31.549 & 23.307 & 28.365 & & \\
lignite & & & & & 33.896 & & & \\
gas & 5.901 & 2.174 & 4.522 & 15.435 & 4.522 & 6.783 & \\
oil & 21.821 & 2.486 & 21.821 & 25.610 & 21.821 & 21.821 & 21.821 \\
CHP-gas & 2.174 & 19.833 & 6.848 & & 2.174 & 2.174 & 2.174 \\
CHP-coal & & 20.217 & 32.459 & & 2.649 & & & 2.649 \\
CHP-oil & 2.486 & & 2.486 & & 2.486 & & & 2.486 \\
CHP-bio & 7.160 & 31.692 & 46.726 & & & 7.160 & & 12.288 \\
CHP-other & & & 83.071 & 15.435 & & & 3.736 & 3.736 \\
\hline
\end{tabular}

Table 6: Emission factors for acidifying emissions (g acid equivalent/MWh) per technology.

\begin{tabular}{lllllllll}
\hline & BEL & DEN & FIN & FRA & GER & NLD & NOR & SWE \\
\hline coal & 80.0 & 57.0 & 172.9 & 170.0 & 66.0 & 17.0 & & \\
lignite & & & & & 96.0 & & & \\
gas & 0.0 & 0.0 & 0.0 & 0.0 & 0.0 & 0.0 & & \\
oil & 21.0 & 1.0 & 3.0 & 130.0 & 2.0 & 2.0 & & 21.0 \\
CHP-gas & 0.0 & 0.0 & 0.0 & & 0.0 & 0.0 & & 0.0 \\
CHP-coal & & 57.0 & 150.0 & & 10.0 & & & 10.0 \\
CHP-oil & 1.0 & & 2.0 & & 2.0 & & & 2.0 \\
CHP-bio & 30.0 & 0.0 & 21.0 & & & 30.0 & & 233.0 \\
CHP-other & & & 195.0 & 0.0 & & & 1.0 & 1.0 \\
\hline
\end{tabular}

Table 7: Emission factors for smog formation ( $\mathrm{g} / \mathrm{MWh})$ per technology. 


\begin{tabular}{llll}
\hline $\begin{array}{l}\text { without } \\
\text { emissions }\end{array}$ & S & P & NS \\
\hline 1 country & E1.1 & E1.2 & E1.3 \\
2 countries & E1.4 & E1.5 & E1.6 \\
8 countries & E1.7 & E1.8 & E1.9 \\
\hline
\end{tabular}

Table 8: Scheme of case studies with no emission restrictions.

\begin{tabular}{llll}
\hline $\begin{array}{l}\text { with } \\
\text { emissions }\end{array}$ & S & P & NS \\
\hline 1 country & E2.1 & E2.2 & E2.3 \\
2 countries & E2.4 & E2.5 & E2.6 \\
8 countries & E2.7 & E2.8 & E2.9 \\
\hline
\end{tabular}

Table 9: Scheme with case studies with emission restrictions.

only 5 electricity producers in the country; electricity transmissions with other countries are not considered. The game solution can be computed analytically (provided that the solution exists), following the algorithm shown in the appendix.

- There are two countries in the model (The Netherlands and Belgium); electricity transmissions between these two countries can be considered; transmissions with other countries are not considered. The solution of the game could be computed analytically or numerically, with the procedure described in the appendix. In general, multiple solutions are possible.

- All 8 countries are included in the model; the electricity transmissions among these 8 countries can be considered. A numerical procedure proposed to solve the problem is described in the appendix, as analytical solution becomes intractable.

In Table 8 and Table 9 schemes of the case studies are depicted. The first table refers to the games without emission constraints. The second table refers to the problems with emission constraints.

In the Stackelberg game we will assume that the leaders have access to the means of electricity production listed in Table 10,

For games with 2 and more countries there will be variant (c), denoting that the cross-border transactions are considered.

\subsection{Games with one country}

\section{Games E1.2 and E2.2}

Maximization of the utility functions with respect to the quantities produced gives the following outcome. With perfect competition (Game E1.2) and with all producers having equal access to the means of electricity production, the selling price of electricity is 17.23 [€/MWh].

When the emission constraints are considered (Game E2.2), the selling price of electricity is 19.13 [€/MWh]. 


\begin{tabular}{lll}
\hline Game & S & NS \\
\hline BEL & wind, hydro, nuclear & wind, hydro, nuclear, CHP-gas \\
DEN & wind, hydro & wind, hydro, CHP-coal, CHP-gas \\
FIN & wind, hydro, nuclear & wind, hydro, nuclear, CHP-gas \\
FRA & wind, hydro & wind, hydro \\
GER & wind, hydro & wind, hydro \\
NLD & wind, hydro, nuclear, CHP-gas & wind, hydro, nuclear, CHP-gas, coal \\
NOR & wind, hydro & wind, hydro \\
SWE & wind, hydro & wind, hydro \\
\hline
\end{tabular}

Table 10: The available means of electricity production for leaders in Stackelberg games.

\section{Games E1.1 and E2.1}

Let the leading producer have access to the means of production listed in Table 10 as the only producer. In Game E1.1 maximization of his/her profit with respect to the constraint of nonnegative profit for other producers leads to a selling cost of 25.98 [€/MWh], yielding him/her a profit of $55182.92[\mathrm{~K} €]$, while the utility of all other producers is zero.

When the emission constraints are considered (Game E2.1), the selling price of electricity is 30.10 [€/MWh] and the profit for the leader is 49819.10 [K€], while the other producers obtain a zero profit.

\section{Games E1.3 and E2.3}

Let the two leading producers as only producers have access to the means of production listed in Table 10. Then maximization of their profit with respect to the constraint of nonnegative profit for other producers leads to a selling cost of 20.31 [€/MWh] and an average profit of 44632.41 [K€], while all other producers have a zero profit.

With emission constraints included the selling cost is 26.15 [€/MWh]. This cost yields profit of 41023.24 [K€] for each of the leading producers, while all other producers have a zero profit.

We observe that for the games with only one country (The Netherlands) of the same type with respect to the emission restrictions the selling electricity price is remarkably higher if there is one Stackelberg leading producer than if there are two Stackelberg leading producers, noncooperative among themselves. Moreover, the game with a perfectly competitive market yields the lowest electricity prices of the three games considered. We claim that in general the increase of competition in the market does not increase the electricity price, if the regulatory restrictions (e.g., restriction of the amount of electricity produced by individual companies) apply. This claim is supported by case studies of the same type that we performed with other countries than The Netherlands.

Application of emission constraints causes electricity price increase unless the original means of electricity production created emissions below the emission constraints.

While the resulting electricity prices for the perfect competition are approximately $25 \%$ lower than those reported in (Lise and Linderhof, 2004) (this might be related 
to the assumption on symmetry of the players), the trends in the prices with respect to the game structure coincide with our expectations on the role of competition in the electricity market.

\subsection{Games with two countries}

\section{Games E1.4 and E2.4}

If Game E1.4 is played, the electricity price in The Netherlands is 19.42 [€/MWh] and yields a profit of $50244.12[\mathrm{~K} €]$ for the leader; the electricity price in Belgium is 22.99 [€/MWh]; the profit of the leading producer will be $61213.24[\mathrm{~K} €]$.

If Game E1.4(c) is played, the electricity price in The Netherlands is 18.35 [€/MWh] and yields a profit of $46001.21[\mathrm{~K} €]$ for the leader; the electricity price in Belgium is 20.85 [€/MWh]; the profit of the leading producer is $57192.91[\mathrm{~K} €]$.

If Game E2.4 is played, the electricity price in The Netherlands is 22.32 [€/MWh] and yields a profit of $44115.23[\mathrm{~K} €]$ for the leader; the electricity price in Belgium is 23.56 [€/MWh]; the profit of the leading producer is $57234.11[\mathrm{~K} €]$.

If Game E2.4(c) is played, the electricity price in The Netherlands will be 20.15 [€/MWh] and yields a profit of $37125.24[\mathrm{~K} €]$ for the leader; the electricity price in Belgium is 22.12 [€/MWh]; the profit of the leading producer is $50259.44[\mathrm{~K} €]$.

\section{Game E1.5 and Game E2.5}

If both Belgium and The Netherlands are considered in the perfect competition case (Game E1.5), 15.41 [€/MWh] and $18.12[€ / \mathrm{MWh}]$ are the selling prices in Belgium and The Netherlands, respectively.

If emission restrictions are included, the prices are $17.99[€ / \mathrm{MWh}]$ and 19.99 [€/ MWh], respectively.

\section{Game E1.6 and Game E2.6}

If both Belgium and The Netherlands have two leading producers, playing Nash among themselves (In Belgium these two producers are the only players). and cross-border electricity transmissions are prohibited (Game E1.6), the game does not have a solution, since the two electricity producers in Belgium cannot cover the demand for electricity. Together they can produce only $7.70[\mathrm{GW}]$ of electricity, while the initial electricity demand in Belgium is 9.04 [GW]. If the demand would not need to be satisfied, the optimal strategy for the identical leaders would be to set the price of electricity infinitely high.

If Game E1.6(c) is played, the situation is solvable. Moreover, the electricity producers in Belgium cannot set the electricity prices arbitrarily high, as they are limited by the electricity prices in The Netherlands. A solution to the problem is as follows: The electricity price in both Belgium and The Netherlands is $20.25[€]$, the average profit of the Dutch producers is $73140.23[\mathrm{~K} €]$, the average profit of Belgian producers is 23095.18 [K€]. If Game E2.6(c) is played, the selling price of electricity for both Belgium and The Netherlands will be $21.31[€]$ and the average profits for the Dutch and Belgian producers will be $65232.13[\mathrm{~K} €]$ and $18123[\mathrm{~K} €]$, respectively.

We note that in the games of the same type with respect to the emission restric- 
tions extending the number of countries to two (The Netherlands and Belgium) does not need to decrease the selling electricity prices in both countries and may even lead to electricity shortages in some of the countries. This is caused by the fact that the producers are motivated to sell their electricity to the neighboring country as long as their marginal revenue is higher there. In general, this might cause shortage of electricity in the country with lower electricity price and therefore necessity to buy the electricity from the neighboring country, which might be not always possible.

Similarly as we reported for the case studies in Section 3.3, also in the case studies with two countries the electricity price within a country is remarkably higher if there is one Stackelberg leading producer than if there are two Stackelberg leading producers, noncooperative among themselves, and the perfectly competitive market yields the lowest electricity prices. Also here the application of emission constraints causes electricity price increase unless the original means of electricity production created emissions below the emission constraints.

\subsection{Games with eight countries}

For each of the three games we will consider both variants with and without electricity transmissions between neighboring countries.

The resulting prices for the base load period are mentioned in Table 11, whereas the amounts of electricity traded between the neighboring countries are given in Table 12. In this table, 1320/1500 in column BEL-FRA illustrates that 1320 [MW] of electricity from Belgian firms will be sold in France, while 1500 [MW] of electricity units will be sold in Belgium by French firms. The amounts of acid particles per firm in a country ([g]), the amounts of $\mathrm{CO}$ particles per firm in a country ([g]), and the resulting amounts of smog particles per firm in a country ([g]) for Game E1.8 are listed in Table 11. If the emission constraints are imposed with standard emission fees (European Transmission System Operators, 2007), the electricity prices may quite drastically increase, while the emissions are indeed lowered.

While it is clear that the perfect competition again yields the lowest electricity prices and that the game with one Stackelberg leader yields the highest electricity prices, and as in the previous cases imposing of emission constraints increases the electricity price, there is no clear answer to the question how the possibility of crossborder electricity trade influences its prices. This claim can be motivated in the same way as it was done for case studies in Section 3.4.

Please note the extremely low electricity prices in Norway under perfect competition. These prices follow from very low production costs in Norway, where only hydropower is used. In a perfect competition the producers keep the selling costs low. There are also no emission restrictions for producers using hydroenergy, and, therefore, the price will stay the same also if the emission restrictions are adopted. Moreover, the price cannot be influenced by producers from neighboring countries, because it is not profitable for them to transmit their electricity to Norway and because whole electricity demand in Norway is covered by their own sources.

\subsection{Discussion}

The outcomes of the case studies are as follows: 


\begin{tabular}{lllllll}
\hline Game & E1.7 & E1.7 (c) & E1.8 & E1.8(c) & E1.9 & E1.9(c) \\
\hline BEL & 25.73 & 23.41 & 15.04 & 13.23 & 20.98 & 18.21 \\
DEN & 20.03 & 19.97 & 5.98 & 5.44 & 14.98 & 14.72 \\
FIN & 20.32 & 20.28 & 7.81 & 5.23 & 15.05 & 14.88 \\
FRA & 20.35 & 19.44 & 11.20 & 12.87 & 17.21 & 16.88 \\
GER & 23.95 & 22.95 & 14.87 & 14.62 & 18.22 & 17.99 \\
NLD & 21.13 & 19.25 & 15.85 & 12.01 & 19.54 & 18.22 \\
NOR & 13.21 & 12.59 & 0.01 & 0.01 & 9.25 & 9.01 \\
SWE & 17.32 & 15.45 & 1.37 & 1.08 & 14.21 & 13.54 \\
\hline
\end{tabular}

Table 11: Resulting selling costs (€/MWh) for base load period for games with 8 countries.

\begin{tabular}{llll}
\hline Game & E1.7(c) & E1.8(c) & E1.9(c) \\
\hline BEL-FRA & $1320 / 1500$ & $0 / 2850$ & $1440 / 1410$ \\
BEL-NLD & $890 / 50$ & $1400 / 0$ & $1000 / 25$ \\
DEN-GER & $1460 / 1300$ & $1750 / 0$ & $1500 / 750$ \\
DEN-NOR & $60 / 800$ & $0 / 950$ & $50 / 900$ \\
DEN-SWE & $210 / 800$ & $0 / 950$ & $100 / 880$ \\
FIN-NOR & $20 / 65$ & $0 / 70$ & $10 / 68$ \\
FIN-SWE & $320 / 1800$ & $0 / 2050$ & $200 / 1900$ \\
FRA-GER & $850 / 275$ & $1150 / 0$ & $910 / 105$ \\
GER-NLD & $2950 / 1500$ & $3300 / 0$ & $3005 / 545$ \\
GER-SWE & $200 / 455$ & $0 / 550$ & $150 / 505$ \\
NOR-SWE & $1420 / 2650$ & $0 / 3035$ & $720 / 2810$ \\
\hline
\end{tabular}

Table 12: Electricity traded (MW) between neighboring countries.

\begin{tabular}{llll}
\hline Game E1.8 & acid & CO & smog \\
\hline BEL & $3.5961 \cdot 10^{4}$ & $1.4191 \cdot 10^{6}$ & $3.5961 \cdot 10^{4}$ \\
DEN & $1.3304 \cdot 10^{3}$ & $3.1320 \cdot 10^{5}$ & $1.3304 \cdot 10^{3}$ \\
FIN & $9.7799 \cdot 10^{4}$ & $2.0925 \cdot 10^{6}$ & $9.7799 \cdot 10^{4}$ \\
FRA & 0 & 0 & 0 \\
GER & $8.2164 \cdot 10^{4}$ & $3.3121 \cdot 10^{6}$ & $8.2164 \cdot 10^{4}$ \\
NLD & $4.3591 \cdot 10^{4}$ & $1.6014 \cdot 10^{6}$ & $4.3591 \cdot 10^{4}$ \\
NOR & 0 & 0 & 0 \\
SWE & $6.2383 \cdot 10^{3}$ & $1.1744 \cdot 10^{6}$ & $6.2383 \cdot 10^{3}$ \\
\hline total & $2.6708 \cdot 10^{5}$ & $9.9127 \cdot 10^{6}$ & $2.6708 \cdot 10^{5}$ \\
\hline
\end{tabular}

Table 13: Game E1.8: Emission of acid particles (g), CO particles (g), and smog particles $(\mathrm{g})$, in different countries per firm 
- For the games of the same type with respect to the existing regulations (presence of cross-border transmission of electricity, emission constraints) the perfect competition implies lower electricity prices than the Stackelberg game with two leaders, which implies higher prices than the Stackelberg game with one leading producer per country.

- The possibility of cross-border electricity transmission does not necessarily decrease the electricity prices in individual countries. Moreover, it may become profitable for some producers to produce more electricity (than they would produce if the cross-border transmission was not allowed) if their marginal production cost is lower than the marginal selling price in the neighboring country. However, with the perfect competition this would mean that the producer gets more resources to be used for more extensive electricity production in the producer's country of origin and may cause problems discussed in Section 3.4.

- The shadow prices imposed if emission constraints are exceeded imply more ecological electricity production, but also increase the electricity prices.

- The resulting electricity prices are lower than the prices in the actual electricity market. This is most probably because not all data about electricity producers in individual countries was known and therefore some simplifying assumptions (e.g., symmetry of the producers in the perfect competition) were made. Similarly, the profits of the electricity producers are much lower than the ones that the electricity producers receive in reality. However, with the additional data known the model can be used for prediction of the European electricity market behavior as it prove to reflect very well the most important trends in the European electricity market.

- The resulting emission levels have not been compared to those from actual measurements yet.

\section{Conclusions \& future research}

\subsection{Conclusions}

We have proposed a model of the liberalized European electricity market, consisting of 8 European countries. In the model emission limitations can be set as well as maximal transmission capacities between the neighboring countries. The aim has been to see how different the electricity prices will be in a situation with one leading producer per country, a situation with two leading producers per country, and a perfectly competitive situation.

Although the considered model is rather simple, some interesting phenomena can be observed:

- The electricity prices become lower when cross-border electricity transmissions are allowed.

- In the situations with one Stackelberg leader and in the situation with two Stackelberg leaders the electricity prices are higher than in the situation with perfectly competitive market. 
- Generally in the perfect competition the producers tend to use cheaper and nonenvironmentally friendly means of electricity production. The emission restrictions are needed to motivate the electricity producers to act more ecologically. This increases the electricity prices, though, especially in the countries with a low number of hydro and wind power plants.

Outcomes of our case studies coincide with the expected outcomes of the liberalization process. However, the following remarks about the practical relevance of the results have to be made:

- In reality, there is a risk that the fully competitive market without regulatory restrictions may lead to a rapid price escalation and market collapse (see (Puller, 2007) and references therein). However, we prevent such undesirable behavior by including regulatory restrictions in the model (e.g., interdiction of overscheduling of the power lines or requirement of electricity price uniformity per country and per load mode).

- The resulting electricity prices and the resulting profits of the electricity producers in our case studies are remarkably lower than those in the current European electricity market. We assume that there are some additional factors, not included into our modeling, influencing the electricity price.

- The model is static.

A dynamic (one step ahead) variant of the existing model is being developed.

\subsection{Model limitations, future research}

The major limitations of the model are:

- In this paper it was assumed that the game is deterministic and that producers have perfect information about all profit functions. This is a first step. Extension of the current research into the situation in which the game is stochastic and into the situation in which the producers have incomplete knowledge of the profit functions is a subject of our future research.

- Only three possible games were considered in each of the case studies: perfect competition, Stackelberg game with one leader, Stackelberg game with two leaders. Although the aim of liberalization is to obtain a highly competitive market, it will never be perfectly competitive. Situations with noncooperative electricity producers, in non-perfect competition have to be considered to obtain more realistic outcome.

- While most data used for the modeling are real, the assumptions on the players' behavior are very strong. For example, in many case studies we considered that perfectly competing producers (acting as followers) have identical utility functions. This of course does not apply in reality.

- Only 8 countries were included in the model, because there were not sufficient data about the rest of European countries.

- Cross-border ownerships of the electricity producers are not allowed in the model, while in reality they appear more and more often. 
- The electricity price is assumed to be constant within one country, while in reality this price might differ per electricity producer (Van Eck, 2007).

Increasing the complexity of the model as well as improving the current solution algorithm are subjects for the future research. The dynamic extension of the model is being developed. In such a dynamic model additional factors, like the life cycle of the different electricity plants, will be included.

\section{Acknowledgments}

This research has been carried out in a close cooperation with the Faculty of Technology, Policy and Management of the Delft University of Technology and has been supported by the Delft Research Center Next Generation Infrastructures, the European 7th framework STREP project "Hierarchical and distributed model predictive control of large-scale systems (HD-MPC)", contract number INFSO-ICT-223854, and by the European 7th Framework Network of Excellence "Highly-complex and networked control systems (HYCON2)". 


\section{Appendix}

\section{Computation of electricity quantities produced by individual elec- tricity producers}

We will discuss solving of the perfect competition problem (P). The algorithm depicted below finds the optimal solution if all producers produce nonzero quantities of electricity by all technologies available to them and transfer the electricity to all countries within $U_{r}$ for each $r$.

If any resulting quantity $q_{i, f, r^{\prime}, l}$ is equal to zero, the corresponding technology and/or transmission is withdrawn from the technology and/or transmission set belonging to the firm $f$ and the algorithm has to be run again with new initial values. This has to be done for all possible combinations of zero quantities. Therefore, the complexity of the algorithm is rather high. However, in the case studies it is often assumed that the perfectly competing producers are identical and this decreases the complexity remarkably.

If multiple solutions are found, the solution minimizing the prices in individual countries is chosen.

\section{Algorithm solving the problem (P)}

\section{Initialization}

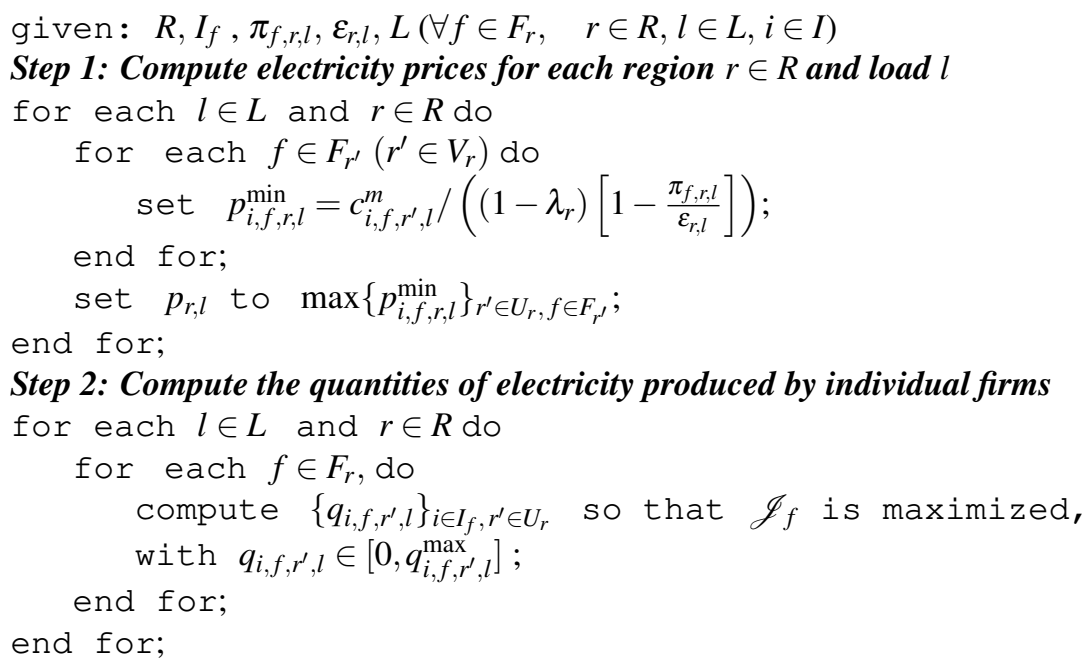

Similarly, for the Stackelberg problems (S) and (NS) the presented algorithm is used to compute the responses of the producers acting as followers when the decisions made by leading producers are fixed. The leading producers maximize their profit as described in Sections 2.5.2 and 2.5.3, respectively, in the outer loop and the algorithm presented here is used in the inner loop.

While the solutions to the problems (P), (S), and (NS) can be computed analytically, it can be also executed in numerical computations. Therefore, we have implemented this algorithm and the corresponding algorithms solving the problems (S) and (NS) in Matlab in order to make the solution more tractable. 


\section{References}

E. S. Amundsen and L. Bergman. The performance of the deregulated electricity markets in Norway and Sweden: A tentative assessment. Technical Report 0798, Department of Economics, University of Bergen, Bergen, Norway, 1998.

B. Andersson. Essays on the Swedish electricity market. PhD thesis, Stockholm School of Economics, Stockholm, Sweden, 1997.

P. S. Armington. A theory of demand for products distinguished by place of production. IMF Staff Papers, 16:159-178, 1969.

K. J. Arrow, H. B. Chenery, B. S. Minhas, and R. M. Solow. Capital-labor substitution and economic efficiency. Review of Economics and Statistics, 43(3):225-250, 1961.

Patrick Beschorner and Frank Ernst. Liberalization of the postal service market in Europe: Entry with universal service and partial coverage. ZEW Discussion Papers 08-122, ZEW - Zentrum für Europäische Wirtschaftsforschung / Center for European Economic Research, Mannheim, Germany, 2008.

M. G. Boots, B. F. Hobbs, and F. A. M. Rijkers. Trading in the downstream European gas market: A successive oligopoly approach. The Energy Journal, 25(3):73-102, 2004.

T. Bye and E. Hope. Deregulation of electricity markets - The Norwegian experience. Discussion Papers 433, Research Department of Statistics Norway, Oslo, Norway, 2005.

Y. Chen and B. F. Hobbs. An oligopolistic power market model with tradable $N O_{x}$ permits. IEEE Transactions on Power Systems, 20(1):119-129, 2005.

J. S. Dodgson. Competition policy and the liberalisation of European aviation. Transportation, 21(4):355-370, 1994.

R. G. Egging and S. A. Gabriel. Examining market power in the European natural gas market. Energy Policy, 34(17):2762-2778, 2006.

L. Ekeberg, L. Sundahl, M. Römpötti, O. S. Halsos, and P. K. Bryng. A powerful competition policy: Towards a more coherent competition policy in the Nordic market for electricity power. Technical Report 1/2003, Nordic competition authorities, 2003.

K. A. Eliassen and M. Sjovaag, editors. European Telecommunications Liberalisation. Routledge Studies in the European Economy. Routledge, London, UK, 1999.

European Transmission System Operators. ETSO server, 2007. URL: http: //www. etso-net.org/.

P. Ganev. Bulgarian electricity market restructuring. Utilities Policy, 17(1):65 -75, 2009.

R. Green. Restructuring the electricity industry in England and Wales. In J. M. Griffin and S. L. Puller, editors, Electricity Deregulation: Choices and Challenges, chapter 2, pages 98-144. The University of Chicago Press, Chicago, 2005. 
B. F. Hobbs, F. A. M. Rijkers, and A. F. Wals. Strategic generation with conjectured price responses in a mixed transmission pricing system - Part I: Formulation. IEEE Transactions and Power Systems, 19:707-717, 2004a.

B. F. Hobbs, F. A. M. Rijkers, and A. F. Wals. Strategic generation with conjectured price responses in a mixed transmission pricing system - Part II: Application. IEEE Transactions and Power Systems, 19:872-879, 2004b.

B. F. Hobbs, F. A. M. Rijkers, and M. G. Boots. The more cooperation, the more competition? A Cournot analysis of the benefits of electric market coupling. The Energy Journal, 26(4):69-98, 2005.

P. Joskow. Lessons learned from electricity market liberalization. The Energy Journal, 29(2):9-42, 2008.

C. J. Koroneos and E. A. Nanaki. Electric energy sustainability in the Eastern Balkans. Energy Policy, 35(7):3826 - 3842, 2007.

M. T. Kromann. Imperfect competition in the Nordic electricity markets. Working Paper 2001:03, Danish Economic Council, Copenhagen, Denmark, 2001.

F. Leveque. Competitive Electricity Markets and Sustainability. Edward Elgar Publishing, Cheltenham, UK, 2007.

W. Lise and V. Linderhof. Electricity market liberalisation in Europe - Who's got the power? Internally reviewed report R-04/03, Institute for Enviromental Studies, Free University, Amsterdam, The Netherlands, 2004.

W. Lise, V. Linderhof, O. Kuik, C. Kemfert, R. Östling, and T. Heinzow. The European electricity market - what are the effects of market power on prices and the environment? Energy Policy, 34(5):2123-2136, 2006.

K. Neuhoff, J. Barquin, M. G. Boots, A. Ehrenmann, B. F. Hobbs, F. A. M. Rijkers, and M. Vázquez. Network-constrained Cournot models of liberalized electricity markets: the devil is in the details. Energy Economics, 27:495-525, 2005.

D. Newbery. Electricity liberalization in Britain and the evolution of market design. In F. Sioshansi and W. Pfaffenberger, editors, Electricity Market Reform: An International Perspective, Elsevier Global Energy Policy and Economics Series, chapter 4, pages 109-144. Elsevier, 2006.

P. O. Pineau and P. Murto. An oligopolistic investment model of the Finnish electricity market. Annals of Operations Research, 121(1-4):123-148, 2003.

M. Pollitt. Evaluating the evidence on electricity reform: Lessons for the South East Europe (SEE) market. Utilities Policy, 17(1):13 - 23, 2009.

S. L. Puller. Pricing and firm conduct in california's deregulated electricity market. The Review of Economics and Statistics, 89(1):75-87, 2007.

K. Staňková. On Stackelberg and Inverse Stackelberg Games \& Their Applications in the Optimal Toll Design Problem, the Energy Market Liberalization Problem, and in the Theory of Incentives. PhD thesis, Delft University of Technology, Delft, The Netherlands, 2009. 
B. Szekely. Liberalisation of the railway industry in Europe: toward a sustainable system through process view. International Journal of Sustainable Economy, 1(2): 167-185, 2009.

E. Van Damme. Liberalizing the Dutch electricity market: 1998-2004. The Energy Journal, 26(I):155-180, 2005.

T. Van Eck. A New Balance for the Energy Sector: No Longer a Puppet in the Hands of Technology, Public Interests and Market. Industrielinqs Pers en Platform, Amsterdam, The Netherlands, 2007. 